\title{
La democracia directa a debate: procesos y mecanismos de participación ciudadana
}

\author{
YANINA WELP* y VICENTE ORDÓÑEZ** \\ * Center for Democracy Studies, Universidad de Zúrich \\ ** Universitat Jaume i de Castelló. Proyecto de investigación «El potencial de las éticas aplicadas \\ EN LAS HERRAMIENTAS DE PARTICIPACIÓN DEL GOBIERNo ABIERTO Y DE LA SOCIEDAD CIVIL» - UJI-A2016-04
}

Que la democracia y los procesos de democratización no siguen caminos unidireccionales hacia un único fin o meta es una evidencia. Volver a leer los debates que se dieron durante la independencia de las colonias americanas y la revolución francesa a fines del siglo xviII y, poco más tarde, durante las discusiones que precedieron a la formación de la Confederación Suiza, son tan solo unas pocas pruebas de lo dicho. Aunque se suele mirar a la Grecia clásica al pensar en los ideales de la democracia, es durante la conformación de los estados modernos cuando surge con fuerza la representación como el mecanismo central para dar fundamento a los nuevos sistemas políticos basados en una legitimidad apoyada en la soberanía del pueblo (una noción de pueblo que se irá ampliando y volviendo más inclusiva con el paso del tiempo). Sin embargo, las discusiones que condujeron a esos modelos (fuertemente centralizado en el caso francés, descentralizado en los otros dos, reservando mecanismos de participación directa en el caso suizo) fueron intensas e involucraron tanto intereses - de las entidades federadas, por ejemplo- como ideas sobre el «deber ser» de los futuros sistemas políticos.

Así, por citar un caso, las discusiones registradas durante la convención de Filadelfia en torno a la figura de la revocatoria de mandato gozan de gran actualidad. En aquel momento triunfaron los que rechazaban dicha institución - el abanderado de la oposición al mecanismo, Alexander Hamilton, sostuvo que la revocatoria convertiría a los legisladores en «esclavos de los caprichosos humores de los ciudadanos» (Spivak, 2004: 22). Pero la historia no es lineal, y lo que no se introdujo en la Constitución se introdujo un siglo más tarde en estados y ciudades de Estados Unidos, comenzado por Oregón, en 1902. Los estados norteamericanos fueron, hasta hace poco, los principales activadores de este mecanismo casi desconoci- 
do en otros lugares, hasta que Perú superó las experiencias norteamericanas acumuladas a lo largo de un siglo, con más de cinco mil referendos en menos de dos décadas (Welp, 2016). Tampoco en Suiza se reguló la revocatoria de mandato a nivel de la Confederación ${ }^{1}$ pero, para que los cantones aceptaran ceder poder al nuevo estado central, fue ineludible introducir el referéndum obligatorio que les permitía una salvaguarda frente a decisiones que rechazaran.Tiempo después se introdujeron otras instituciones de participación constitutivas del particular sistema suizo, que combina de forma inseparable descentralización y activa utilización de mecanismos de democracia directa a nivel local, cantonal y federal.

Los dos párrafos precedentes sirven para poner en perspectiva el momento actual, de fuerte cuestionamiento de las instituciones vigentes y apuesta por reformular y renovar un sistema político acosado por la necesidad de revitalización. La profunda crisis política que atraviesa Europa, por citar un contexto cercano, está provocando no solo el cuestionamiento de la política contemporánea, sino también el de sus mismas bases teóricas, poniendo en tela de juicio los alcances y límites de la representación (Tormey, 2014). La idea de revitalizar la democracia surge, en este escenario, nutriéndose de la expectativa de ampliar los espacios de intervención de la ciudadanía en la definición de los asuntos públicos (Cortina, García Marzá y Conill, 2008).

Con otros condicionantes y circunstancia - el de la recuperación y expansión de la democracia - la apuesta por la participación ciudadana institucional ya se había comenzado a expandir en América Latina desde fines de los ochenta. El resultado es que en la actualidad numerosas son las experiencias - por ejemplo, presupuestos participativos, auditorías ciudadanas o consultas populares - que se han desarrollado con esta intención en distintos lugares del mundo (Font et al., 2014; Geissel y Newton, 2012; Lissidini et al., 2014).

A nivel de los gobiernos centrales, en las últimas décadas se ha observado una tendencia a regular mecanismos de democracia directa, como el referéndum o la iniciativa popular, especialmente en América Latina y los países de Europa del Este (Serdült y Welp, 2012). La Unión Europea, por su parte, ha sido la región del mundo que con mayor frecuencia ha activado estos mecanismos, asociados al proceso de integración, mientras recientemente se ha introducido la Iniciativa Ciudadana Europea, como una experiencia inédita aunque con carácter indirecto y consultivo (Ruth et al. 2017). Pero estos procesos de innovación democrática, que recuperan me-

1 Sí está regulado en seis cantones (véase Serdült, 2015). 
canismos ya conocidos aunque poco utilizados o producen nuevas instituciones, no solo no se circunscriben al nivel nacional o supranacional sino que han tenido como especial protagonista al gobierno local, tanto en América Latina (Porto Alegre o Montevideo, como ejemplos ya clásicos) como en Europa (Barcelona, Bolonia y Madrid, entre otras).

Aquí las nuevas tecnologías están haciendo una contribución relevante permitiendo superar las trabas a la acción colectiva que impone la coordinación en el tiempo y el espacio, a menudo sostenidas como argumento contra formas de participación directas y deliberativas. En este proceso heterogéneo, algunos mecanismos de participación ciudadana han sido integrados en el repertorio político de las democracias representativas con cierta naturalidad. No se trata tanto de una dicotomía entre el principio representativo y la democracia directa como de la progresiva incorporación de elementos de participación ciudadana en el funcionamiento de las instituciones representativas. Sin embargo, en otros casos estos mecanismos son objeto de disputa entre gobiernos locales y centrales, entre una ciudadanía que reclama su regulación o trabaja para activarlos y unos gobiernos que se resisten a permitirlos. El espectro de experiencias es múltiple como lo son también sus resultados.

En este número de la revista Recerca queremos analizar críticamente las posibilidades y límites de los mecanismos de participación ciudadana con el objetivo de tener una mejor perspectiva de las tensiones, contradicciones, ajustes y desajustes que tienen lugar en el ecosistema democrático (Dekker y Feenstra, 2015): ¿bajo qué condiciones pueden esos mecanismos contribuir a un mayor empoderamiento ciudadano, implementar herramientas de transparencia y generar procesos de fortalecimiento de la democracia? ¿Cómo conciliar la participación directa con las formas políticas tradicionales? ¿Cuáles son los límites de la participación ciudadana en las sociedades postindustriales?

Recerca aborda estas cuestiones con un número doblemente especial, especial por estar dedicado a una temática exclusiva pero también por su formato, en el que combina artículos de investigación con textos centrados en las experiencias recientes de Madrid y Barcelona, breves comentarios de expertos y una selección de reseñas de libros que tratan sobre la temática del dosier.

Los artículos de investigación abordan desde casos y perspectivas diferentes la cuestión de la participación ciudadana directa. Sandra Hincapié lo hace con un análisis de los mecanismos regulados y las consultas populares que se han producido en torno a conflictos socioambientales en América Latina («Entre el extractivismo y la defensa de la democracia. Me- 
canismos de democracia directa en conflictos socioambientales en América Latina»). Su análisis ofrece información sistemática en un campo de creciente conflictividad, no solo entre ciudadanía y representantes, sino también entre unidades de gobierno, siendo el espacio local clave en la disputa. La autora observa que a pesar de las movilizaciones «desde abajo», las consultas han tendido a estar controladas por las autoridades, observando que la participación de la ciudadanía se ha convertido en parte de las promesas incumplidas de los procesos de democratización y descentralización.

Desde el caso mexicano y con énfasis en las innovaciones orientadas a innovar en los mecanismos de participación, el artículo "Las candidaturas independientes en México: una experiencia paradójica», de Jorge Aguirre Sala, Marco Antonio Aranda, José María Infante y José Ruiz, evalúa el desempeño democratizador de las candidaturas independientes (aquellas que no requieren afiliación partidaria a sus postulantes). Los autores observan que, pese a la relativa expansión del mecanismo, su diseño institucional plantea controversias, ya que son desiguales los requisitos exigidos a los partidos y a las candidaturas independientes, mientras las prácticas parecen abrir nuevas ventanas de oportunidad para políticos tradicionales que enfrentan conflictos al interior de sus partidos.

Con la mirada puesta sobre los procesos recientes en Europa, John Postill propone su «Field theory, media change and the new citizen movements: Spain's 'real democracy' turn as a series of fields and spaces». El autor analiza, centrándose en las teorías de Bourdieu y en el análisis del Movimiento 15M (o Indignados) en España, cómo los cambios políticos recientes en el plano de la acción colectiva no se dan en torno a un flujo continuo sino como una serie de eventos discretos y efímeros que el autor denomina «dispersed civic space».

Los hacedores de las políticas de participación de más reciente desarrollo en Barcelona y Madrid también tienen su espacio en el número. Por Barcelona, Antonio Calleja aporta una explicación de los principios y funcionamiento de la Plataforma Decidim. También desde la ciudad condal Marta Molas presenta un resumido pero muy completo análisis de los alcances y tensiones generados por el desarrollo de políticas favorables a la economía social y colaborativa basado en entrevistas a responsables políticos y sociales. Desde Madrid, la entrevista de Fernando Navarro a Yago Bermejo, responsable de la implementación del proceso participativo Madrid G1000, también hace su aporte a comprender los retos y expectativas de lo que ha dado en llamarse la nueva política en la península. Estos tres textos son acompañados de ensayos breves de Joan Font y Yanina Welp, 
que buscan poner en perspectiva (histórica en el caso de Font, comparando España con los procesos latinoamericanos en el caso de Welp) la innovación democrática.

Las reseñas completan el número con perspectivas históricas y comparadas, más académicas o más periodísticas, centradas en experiencias y momentos históricos concretos o desde enfoques más teóricos. Los libros presentados son La reconfiguración de la democracia: el laboratorio político español (2017), editado por Ramón Feenstra, Simón Tormey, Andreu Caseró-Ripollés y John Keane (reseña de Critian Osal López); Mañana. Viaje a la España del cambio (2017), de Bernardo Gutiérrez (reseña de Micaela Días Rosaenz); Popular Democracy: the Paradox of Participation (2017), de Gianpaolo Baiocchi y Ernesto Ganuza (reseña de Valentín Lucas Viedma); Let the people rule? Direct democracy in the twenty-first century (2017), editado por Saskia Ruth, Yanina Welp y Laurence Whitehead (reseña de Pedro Capra) y The End of Representative Politics (2015), de Simon Tormey (reseña de Lasse Thomassen).

\section{BIBLIOGRAFÍA}

Cortina, A., García Marzá, D. y Conill, J. (eds.) (2008): Public Reason and Applied Ethics: The Ways of Practical Reason in a Pluralist Society, Londres, Routledge.

DekKer, P. y Feenstra, R. (2015): «Activism and Civil Society: Broadening Participation and Deepening Democracy», Recerca. Revista de Pensament i Anàlisi, núm. 17, pp. 7-13.

Font, J., Della Porta, D. y Sintomer, Y. (2014): Participatory Democracy in Southern Europe: Causes, Characteristics and Consequences, Londres, Rowman \& Littlefield International.

Geissel, B. y Newton, K. (2012): Evaluating Democratic Innovations - Curing the Democratic Malaise?, Abingdon, Routledge.

Lissidin, A., Welp, Y. yy Zovatto, D. (eds.) (2014): Democracias en Movimiento, México, Instituto de Investigaciones Jurídicas - UNAM.

Ruth, S., Whitehead, L. yy Welp, Y. (eds.) (2017): Let the people rule? Direct democracy in the twenty-first century, Colchester, ECPR Press.

SERDÜLT, U. (2015): «A dormant institution - history, legal norms and practice of the recall in Switzerland», Representation - Journal of Representative Democracy, 51(2): 161-172.

Serdült, U. y Welp, Y. (2012): «Direct Democracy Upside Down», Taiwan Journal of Democracy 8 (1): 69-92. 
SpIVAK, J. (2004): «California's Recall. Adoption of the 'Grand Bounce' for Elected officials», California History 81, n. ${ }^{\circ} 2$.

Tormey, S. (2014): The End of Representative Politics, Londres, Wiley.

Welp, Y. (2016): «Recall referendums in Peruvian municipalities: a political weapon for bad losers or an instrument of accountability?», Democratization 23 (7): 1162-1179. 